\title{
Contribution of nestin positive esophageal squamous cancer cells on malignant proliferation, apoptosis, and poor prognosis
}

\author{
Beilong Zhong ${ }^{1+}$, Tao Wang ${ }^{2,3^{*}}$, Xueping Lun 4,5,6, Jinli Zhang ${ }^{7}$, Sannv Zheng ${ }^{8}$, Weilin Yang ${ }^{4,5,6}$, Weiqiang Li ${ }^{2,3}$, \\ Andy Peng Xiang ${ }^{2,3}$ and Zhenguang Chen ${ }^{4,5,6^{*}+}$
}

\begin{abstract}
Background: The stem cell-associated intermediate filament nestin has recently been linked with neoplastic transformation, but the specific mechanism by which nestin positive tumor cells leads to malignant invasion and metastasis behaviors of esophageal squamous cell carcinoma (ESCC) remains unclear.
\end{abstract}

Methods: To obtain insight into the biological role of nestin in ESCC, we explored the association of the nestin phenotype with malignant proliferation and apoptosis in esophageal squamous cancer cells. Nestin expression was determined in ESCC specimens and cell lines, and correlated with clinicopathological properties, including clinical prognosis and proliferative markers. The association of the nestin phenotype with apoptotic indicators was also analyzed.

Results: Nestin was expressed in ESCC specimens and cell lines. ESCC patients with nestin-positive tumors had significantly shorter median survival and progression-free survival times than those with nestin-negative tumors. Positive staining for the proliferation markers Ki67 and PCNA (proliferating cell nuclear antigen) was detected in $56.9 \%$ and $60.2 \%$ of ESCC specimens, respectively, and was strongly correlated with the nestin phenotype. Notably, expression of cyclin dependent kinase-5 (CDK5) and P35 was detected in 53.8\% and 48.4\% of ESCC specimens, respectively, and was strongly associated with the nestin phenotype.

Conclusion: Our data demonstrated nestin expression in ESCC specimens and cell lines, and revealed a strong association of the nestin phenotype with poor prognosis in ESCC patients. Furthermore, we showed that nestin positive ESCC cells played an important role in the malignant proliferation and apoptosis.

Keywords: Esophagus, Cancer, Esophageal squamous cell carcinoma, Nestin, Intermediate filament, Proliferation, Apoptosis

\section{Introduction}

Esophageal cancer is a malignancy of the esophagus common throughout the world that is characterized by its high invasiveness and mortality. Histologically, more than $90 \%$ of esophageal cancers are either esophageal squamous cell carcinomas (ESCCs) or esophageal adenocarcinomas (EACs); in China, ESCC is the predominant

\footnotetext{
*Correspondence: wangt69@mail.sysu.edu.cn; chenzhenguang@yahoo.com ${ }^{\dagger}$ Equal contributors

${ }^{2}$ Center for Stem Cell Biology and Tissue Engineering, Sun Yat-sen University, Key Laboratory for Stem Cells and Tissue Engineering, Ministry of Education, Guangzhou, Guangdong, China

${ }^{4}$ Department of Thoracic Surgery, the First Affiliated Hospital, Sun Yat-sen University, Guangzhou, Guangdong 510080, China

Full list of author information is available at the end of the article
}

histological subtype and accounts for nearly $90 \%$ of all esophageal cancers [1,2]. Despite considerable advancements in surgical techniques and multidisciplinary treatments based on chemotherapy and radiotherapy, the overall 5-year survival rate of ESCC patients has remained low $(15 \%-39 \%)$ [3]. The current view is that the failure of ESCC treatments reflects the frequent recurrence and metastasis of this cancer type. These phenomena involve several events, including proliferation and invasion of the primary tumor, sustained lymphangiogenesis, and evasion of apoptosis; of these steps, proliferation of the primary tumor appears to be an integral feature of the molecular and cellular pathogenesis and metastasis of esophageal cancer $[4,5]$.

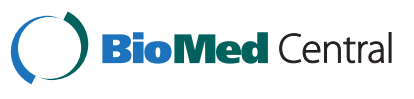

(c) 2014 Zhong et al.; licensee BioMed Central Ltd. This is an Open Access article distributed under the terms of the Creative Commons Attribution License (http://creativecommons.org/licenses/by/4.0), which permits unrestricted use, distribution, and reproduction in any medium, provided the original work is properly credited. The Creative Commons Public Domain Dedication waiver (http://creativecommons.org/publicdomain/zero/1.0/) applies to the data made available in this article, unless otherwise stated. 
Nestin is a member of the class VI family of intermediate filament proteins. Nestin was first identified as a protein expressed in progenitor cells of the central and peripheral nervous systems, but has since also been found in other tissues [6,7]. Notably, it has been proposed that nestin may be a proliferative and multipotency potential indicator in several types of progenitor cells [8-13]. Recent reports have linked nestin with malignant characteristics in different cancers and suggested that abundant nestin positive cancer cells correlate with greater malignancy and poor prognosis [14-17]. We previously demonstrated that the majority of tumor cells in non-small cell lung cancer samples are nestinpositive and showed that nestin expression was positively correlated with the subset of lung cancer patients displaying poor outcomes and high levels of proliferative markers $[18,19]$. Subsequent studies have revealed that nestin knockdown inhibits cell proliferation and G1/S arrest in human non-small cell lung cancer cells, possibly via downregulation of AKT-GSK3 $\beta$-cyclin D signaling. However, the specific function of nestin positive tumor cells in the invasive and metastatic behaviors of esophageal cancer remains unclear. Thus, the precise mechanisms of nestin positive cancer cells action in the proliferation and metastasis of ESCC require further elucidation.

In the present study, we sought to characterize the nestin phenotype in ESCC of Chinese population and assess its association with esophageal cancer cell proliferative properties and clinical prognosis and pathological parameters. Because no previous studies have provided detailed information on signaling mechanisms involved in the proliferation of esophageal cancer cells relevant to the nestin phenotype, we further investigated the mechanism underlying this linkage.

\section{Materials and methods Tissue specimens}

A total of 93 ESCC samples were randomly selected from our tissue database. Samples were obtained from patients treated in the Department of Thoracic Surgery from the First Affiliated Hospital of Sun Yat-sen University between September 2005 and March 2009. The selection criteria included: 1) all cases were confirmed by histopathology; 2) all cases were performed the esophagectomy treatment; 3 ) at least six lymph nodes were examined for pathological diagnosis; 4) none of the patients had received neoadjuvant chemotherapy or radiotherapy. Clinical information was obtained by reviewing preoperative and perioperative medical records or via telephone or written correspondence. Cases were staged based on the tumornode-metastasis (TNM) classification of the International Union Against Cancer, revised in 2002 [20,21]. The use of human materials was approved by the Medical Ethical
Committee of The First Affiliated Hospital, Sun Yat-sen University (No. 2008-7). Clinical characteristics of patients were shown in Table 1.

\section{Cell lines}

The esophageal squamous cell cancer cell lines, Eca-109 and TE-1, were obtained from the Cell Bank of the Chinese Academy of Sciences (Shanghai, China), and cultured according to the specific cell bank protocol.

\section{Immunohistochemical staining}

The immunohistochemical procedure was similar to previously reported protocols $[18,19,22]$. Anti-nestin (AB5922; Millipore, Temecula, CA, USA; 1:500 dilution), anti-Ki-67 (SC-15402; Santa Cruz Biotechnology, Santa Cruz, CA, USA; 1:500 dilution), anti-PCNA (PC10; Cell Signaling Technology, Danvers, MA, USA; 1:4000 dilution), anti-CDK5 (SC-6247; Santa Cruz Biotechnology; 1:1000 dilution), and P35 (SC-820; Santa Cruz Biotechnology; 1:400 dilution) were used as primary antibodies. Ki67 and PCNA staining in ESCC tissue samples was quantified with an optical density-based method using Image-Pro plus 6.0 software (Media Cybernetics, Inc.; Rockville, MD, USA). Double staining of nestin and $\mathrm{Ki}-67$ or nestin and PCNA were processed using strept avidin-biotin complex (SABC) reagent (MXB, KIT-9999, China) and biotinylated antibody was used as secondary antibody [23].

\section{RT-PCR analysis}

Total RNA was extracted, and amplified by reverse transcription-polymerase chain reaction (RT-PCR) using the following primer pairs: nestin, 5'-GAG GAC CAG AGT ATT GTG AGA C-3' and 5'-CAC AGT GGT GCT TGA GTT TC-3 (368 bp); and $\beta$-actin (internal control), 5'-GTG GGG CGC CCC AGG CAC CA-3 and 5-CTC CTT AAT GTC ACG CAC GAT TTC-3' (540 bp).

\section{Immunoblotting analysis}

Proteins were separated, electrotransferred to polyvinylidene difluoride (PVDF) membranes, blocked with a solution of Tris-buffered saline containing $0.1 \%$ Tween20 (TBST), incubated with mouse anti-nestin antibody (AB5922; Millipore; 1:500 dilution) overnight, and detected with a horseradish peroxidase-conjugated antimouse secondary antibody (Cell Signaling Technology). An anti-GAPDH (glyceraldehyde-3-phosphate dehydrogenase) antibody (SC-81545; Santa Cruz Biotechnology) was used as an internal control.

\section{Statistical analysis}

All calculations were performed using SPSS V.14.0 statistical software (Chicago, IL, USA). T-tests, Pearson's and Spearman's coefficient of correlation, logistic regression, 
Table 1 Association of nestin expression with clinicopathological features in ESCC

\begin{tabular}{|c|c|c|c|c|c|}
\hline & \multirow[t]{2}{*}{ Characteristics } & \multirow[t]{2}{*}{ No. of patients } & \multicolumn{2}{|c|}{ Nestin expression $n(\%)$} & \multirow[t]{2}{*}{$P$-value } \\
\hline & & & Positive & Negative & \\
\hline \multirow[t]{2}{*}{ Gender } & Male & 72 & $24(33.3)$ & $48(66.7)$ & 0.686 \\
\hline & Female & 21 & $8(38.1)$ & $13(61.9)$ & \\
\hline \multirow[t]{2}{*}{ Age (y) } & $\leq 60$ & 51 & $16(31.4)$ & 35 (68.6) & 0.497 \\
\hline & $>60$ & 42 & $16(38.1)$ & $26(61.9)$ & \\
\hline \multirow[t]{3}{*}{ Differentiation } & Poor & 32 & $6(18.7)$ & $26(81.3)$ & 0.070 \\
\hline & Moderate & 44 & $19(43.2)$ & $25(56.8)$ & \\
\hline & Well & 17 & $7(41.2)$ & $10(58.8)$ & \\
\hline \multirow[t]{3}{*}{ TNM stage } & । & 5 & $1(20)$ & $4(80)$ & 0.133 \\
\hline & $\|$ & 56 & $23(41.1)$ & $33(58.9)$ & \\
\hline & $I I I+I V$ & 32 & $9(30.8)$ & $23(69.2)$ & \\
\hline \multirow[t]{2}{*}{ Lymph nodes } & Positive & 34 & $9(26.5)$ & $25(73.5)$ & 0.221 \\
\hline & Negative & 59 & $23(39.0)$ & $36(61.0)$ & \\
\hline \multirow[t]{2}{*}{ Ki67 expression } & Positive & 53 & $23(43.4)$ & $30(56.6)$ & 0.036 \\
\hline & Negative & 40 & $9(22.5)$ & $31(77.5)$ & \\
\hline \multirow[t]{2}{*}{ PCNA expression } & Positive & 56 & $26(46.4)$ & $30(53.6)$ & 0.003 \\
\hline & Negative & 37 & $6(16.2)$ & $31(83.8)$ & \\
\hline \multirow[t]{2}{*}{ CDK5 expression } & Positive & 50 & $23(46.0)$ & $27(54.0)$ & 0.022 \\
\hline & Negative & 43 & $10(23.3)$ & $33(76.7)$ & \\
\hline \multirow[t]{2}{*}{ P35 expression } & Positive & 45 & $24(53.3)$ & $21(46.7)$ & 0.031 \\
\hline & Negative & 48 & $15(31.2)$ & $33(68.8)$ & \\
\hline
\end{tabular}

${ }^{*}$ Chi-square test.

or Chi-square tests were applied as appropriate. Median survival time (MST) and progression-free survival time (PFS) were calculated from the date of surgery until the date of tumor recurrence and last follow-up, and the association of nestin expression with MST and PFS was presented as Kaplan-Meier plots. Univariate and multivariate analyses were performed using Cox proportional hazards regression to determine the prognostic effects of nestin expression and potential clinical variables on MST and PFS.

\section{Results}

\section{Basic clinical information and follow-up studies}

In total, 72 male and 21 female patients with esophageal cancer subjected to curative surgical resection were enrolled in the study. The mean age of patients was $60.96 \pm$ 9.98 years (range, 38 to 86 years). All cases were esophageal squamous cell cancer. Cases were classified as stage I $(n=5)$, stage II $(n=56)$, stage III $(n=28)$ and stage IV $(n=4)$, and categorized according to differentiation status as poor $(n=32)$, intermediate $(n=44)$, and well differentiated $(\mathrm{n}=17)$. Patient data were analyzed after 5-years of follow-up, and information was obtained for $94.6 \%$ (88 of 93) of patients. Pathological characteristics of patients are shown in Table 1.

\section{Nestin expression in ESCC tissue specimens}

Using immunohistochemical scoring methods and optical density statistical software, we estimated nestin antibody staining results qualitatively and quantitatively. Among all tissue specimens, 32 cases (34.4\%) were nestin positive (Figure $1 \mathrm{~A}$ and $\mathrm{B}$ ) and 61 cases (65.6\%) were nestin negative (Figure $1 \mathrm{C}$ and D). Regarding to the heterogeneity of nestin staining intensity, the mean optical density was 0.141 (minimum: 0.090; maximum: 0.231 ) in positive cases and was 0.042 (minimum: 0.002; maximum: 0.089) in negative cases. As shown in Figure 1, nestin expression in tumor cells was detected in both the cytoplasm and nucleus.

\section{Nestin expression in ESCC cell lines}

To further examine the expression status of nestin in ESCC, we examined its expression patterns in the ESCC cell lines, Eca-109 and TE-1. Nestin mRNA and protein were detected in both cell lines (Figure 2A and B).

\section{Association of nestin expression with poor prognosis in ESCC patients}

The baseline characteristics of the study population with regard to the nestin phenotype and the results of multivariate analyses are presented in Tables 1 and 2, 

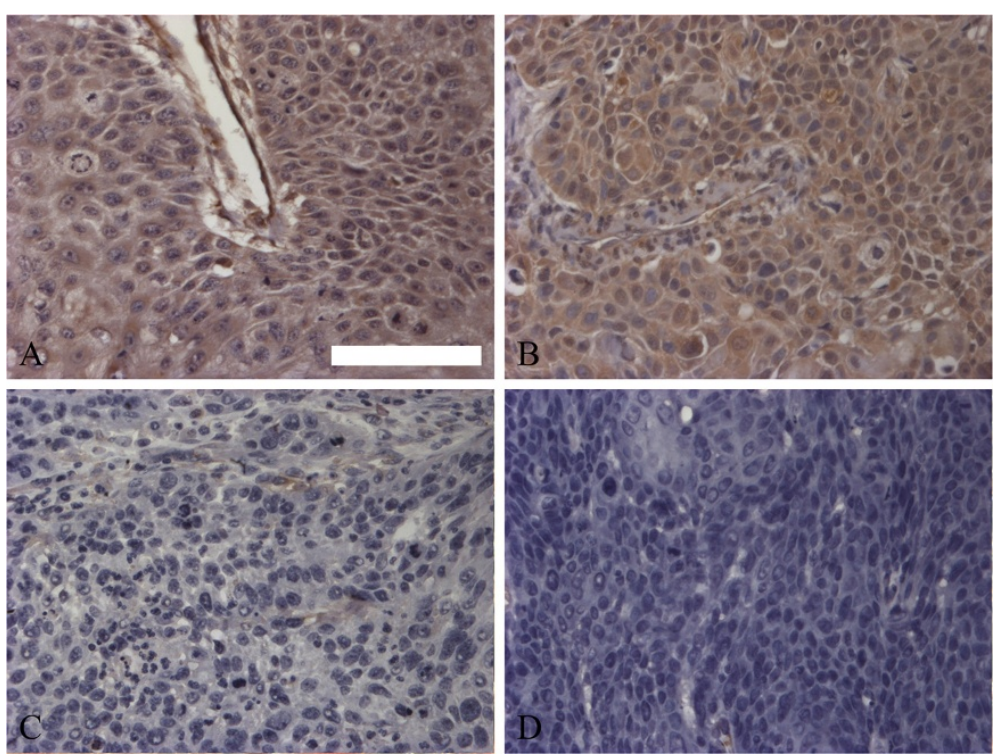

Figure 1 Nestin expression in the cytoplasm and nucleus of ESCC specimens. (A and B) Nestin-positive staining; (C and $\mathbf{D})$ weak or negative nestin staining (Scale bar, $100 \mu \mathrm{m}$ ).

respectively. In the study population as a whole, MST was $15.2 \pm 4.2$ months (95\% CI: 13.3 - 16.7 months). Considering subpopulations based on nestin expression status, the MST of nestin-positive patients $(8.3 \pm$ 2.4 months, 95\% CI: 5.7 - 10.3 months) was significantly shorter than that of nestin-negative patients $(16.0 \pm 5.34$ months, $95 \%$ CI: $14.9-17.1$ months; $P=$ 0.023; Figure 3A). PFS for the entire study population was $12.4 \pm 3.9$ months (95\% CI: 10.4 - 4.4 months). As was the case for MST, PFS was significantly shorter for nestin-positive patients $(9.3 \pm 3.0$ months, $95 \%$ CI: 6.6 11.9 months) than for nestin-negative patients $(14.0 \pm$ 4.1 months, 95\% CI: 11.4 - 16.7 months; $P=0.005$; Figure 3B). A multivariate statistical analysis (Table 2) showed that nestin was a significant prognostic indicator independent of other clinical and pathological factors (HR: $1.586 ; P=0.047$ ).

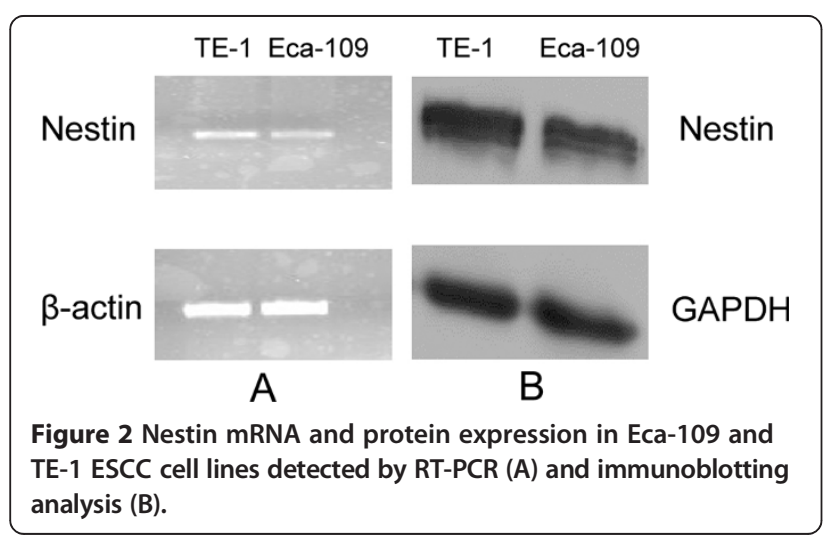

Association of nestin with tumor cell proliferative markers Expression of the proliferative markers Ki67 and PCNA in ESCC tissue samples was determined by immunohistochemical staining. Of the 93 cases of ESCC, 53 (56.9\%) were positive for the expression of Ki67, which was mainly nuclear (Figure 4A), and 40 (43.1\%) were negative for Ki67 expression (Figure 4B). Similar results were obtained for the expression of PCNA; in 56 cases (60.2\%), cells were positive for PCNA expression (Figure 4C) and in 37 cases (43.1\%), cells were negative for PCNA expression (Figure 4D). As expected, PCNA expression was mainly detected in ESCC nuclei (Figure 4C). Ki67 and PCNA expression was quantified (Table 3) using an optical density scoring method employing image analysis software (see Materials and Methods). As shown in Figure 5 (A and B) and Table 1, a subsequent Pearson's correlation analysis revealed a significant relationship between the nestin phenotype and Ki67 and PCNA optical density (Ki67: $r=0.223, P=0.036$; PCNA: $r=0.328, P=$ 0.003). As shown in Figure 6, double staining of nestin and Ki-67 or nestin and PCNA was performed and revealed the status of proliferation of nestin-positive cells.

\section{Association of nestin with tumor cell apoptotic markers}

As a first step toward identifying the signaling pathway underlying the nestin phenotype, we assessed the expression of P35 and CDK5 (cyclin-dependent kinase 5), which is regulated by P35, in ESCC specimens. Of the 93 samples, 50 (53.8\%) were positive for CDK5 and 45 (48.4\%) were positive for P35 (Figure 4). CDK5 and P35 expression were detected in both nuclei and cytoplasm of ESCC cells. As shown in Figure 5, an analysis of the 
Table 2 Univariate and multivariate analyses of nestin expression in relation to median survival time of ESCC patients

\begin{tabular}{|c|c|c|c|c|c|c|}
\hline \multirow[t]{2}{*}{ Variable } & \multicolumn{3}{|c|}{ Univariate analysis } & \multicolumn{3}{|c|}{ Multivariate analysis } \\
\hline & HR & $95 \% \mathrm{Cl}$ & $P$-value & HR & $95 \% \mathrm{Cl}$ & $P$-value \\
\hline \multicolumn{7}{|l|}{ Nestin expression } \\
\hline Positive & 1.579 & $1.025-2.432$ & 0.038 & 1.586 & $1.007-2.499$ & 0.047 \\
\hline Negative & 1.000 & & & 1.000 & & \\
\hline \multicolumn{7}{|l|}{ Differentiation } \\
\hline Poor & 0.680 & $0.442-1.049$ & 0.081 & 0.658 & $0.412-1.053$ & 0.080 \\
\hline Moderate and well & 1.000 & & & 1.000 & & \\
\hline \multicolumn{7}{|l|}{ TNM classification } \\
\hline$I I I+I V$ & 1.268 & $0.820-1.961$ & 0.286 & 0.862 & $0.201-3.692$ & 0.842 \\
\hline $1+\|$ & 1.000 & & & 1.000 & & \\
\hline \multicolumn{7}{|l|}{ Sex } \\
\hline Male & 1.181 & $0.716-1.946$ & 0.515 & 1.397 & $0.826-2.363$ & 0.212 \\
\hline Female & 1.000 & & & 1.000 & & \\
\hline \multicolumn{7}{|l|}{ Age } \\
\hline$\geq 60$ years & 0.881 & $0.582-1.334$ & 0.550 & 0.755 & $0.486-1.172$ & 0.210 \\
\hline$<60$ years & 1.000 & & & 1.000 & & \\
\hline \multicolumn{7}{|c|}{ Lymph nodes metastasis } \\
\hline With & 1.330 & $0.864-2.048$ & 0.195 & 1.870 & $0.451-7.757$ & 0.388 \\
\hline Without & 1.000 & & & 1.000 & & \\
\hline
\end{tabular}

Abbreviations: HR hazard ratio; $L N$ lymph nodes.

${ }^{*}$ Chi-square test.

relationship between CDK5 and P35 expression, quantified using an optical density-based scoring method (Table 3), and the nestin phenotype revealed a significant Pearson's correlation coefficient (CDK5: $r=0.240, P=$ 0.022; P35: $r=0.261, P=0.031$ ).

\section{Discussion}

Nestin was initially discovered based on its expression in neural progenitor cells, where it was considered a marker for distinguishing precursor cells from differentiated cells $[24,25]$. Subsequent reports have shown that

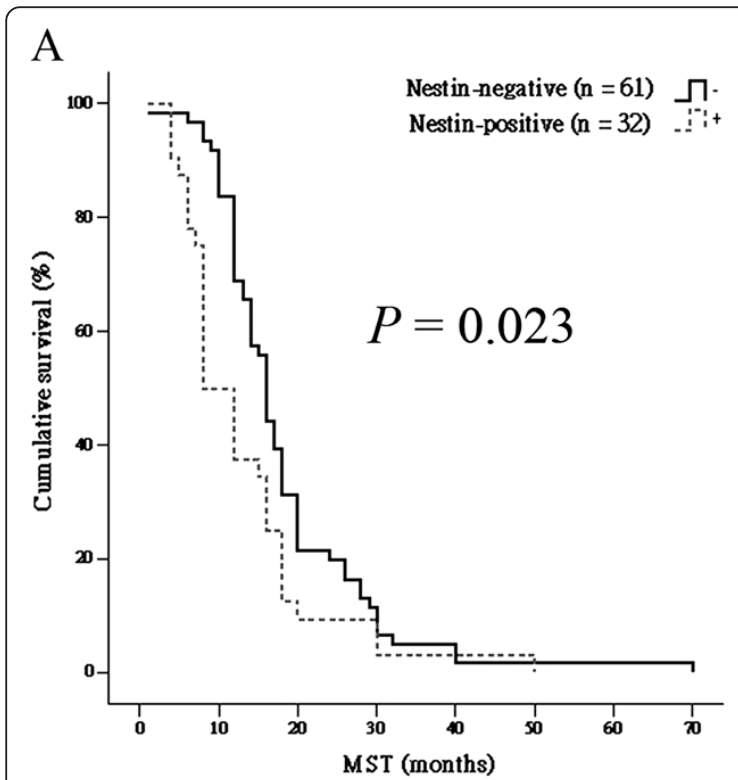

B

Figure 3 Kaplan-Meier plot depicting the differences in MST (A) and PFS (B) between nestin-positive and -negative groups, dichotomized based on the median value of nestin expression in tumor lesions. ${ }^{*} P<0.05$ (ANOVA).

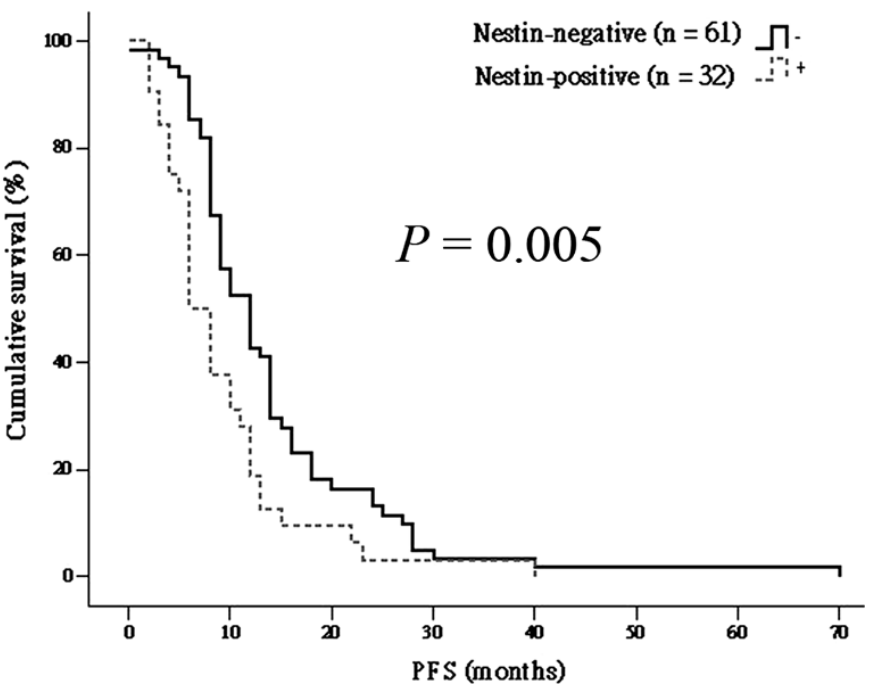




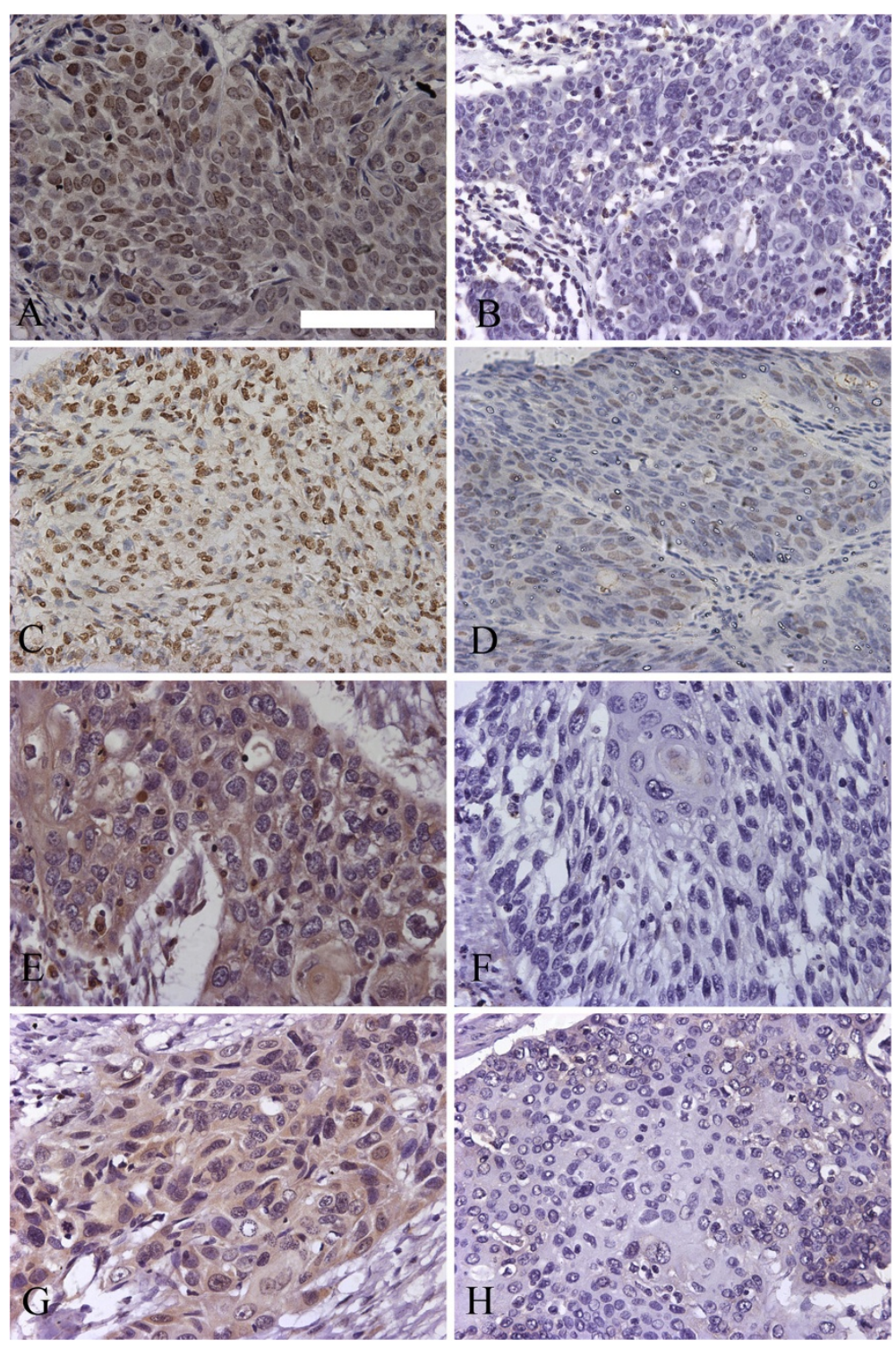

Figure 4 Strong (A) and weak (B) Ki67 staining in ESCC specimens; strong (C) and weak (D) PCNA staining in ESCC specimens; strong $(E)$ and weak (F) CDK5 staining in ESCC specimens; strong (G) and weak (H) P35 staining in ESCC specimens (Scale bar, $100 \mu \mathrm{m}$ ).

Table 3 Association of nestin expression with Ki67, PCNA, CDK5 and P35 expression, determined using an optical density method

\begin{tabular}{lccc}
\hline & Nestin-positive & Nestin-negative & $\boldsymbol{P}_{\text {-value }}$ \\
\hline Ki67 & $0.0124 \pm 0.0033$ & $0.0057 \pm 0.0010$ & $<0.0001$ \\
PCNA & $0.1318 \pm 0.0060$ & $0.0831 \pm 0.0052$ & $<0.001$ \\
CDK5 & $0.2609 \pm 0.0120$ & $0.2140 \pm 0.0053$ & $<0.001$ \\
P35 & $0.2050 \pm 0.0118$ & $0.1478 \pm 0.0100$ & $<0.0001$ \\
\hline
\end{tabular}

*Chi-square test. nestin is expressed in breast, prostate and pancreatic cancer, and is positively correlated with tumor malignancy $[15,26,27]$. Sustained expression of nestin in spindle cells or epithelial cells of esophageal leiomyoma has also been reported [28]. However, no studies have examined nestin expression in ESCC.

Here, we first established that nestin is expressed in $34.4 \%$ of ESCC samples in Chinese population, a result similar to that reported for lung squamous cell carcinoma (35.5\%) and our previous findings in NSCLC $[19,29]$. Consistent with these findings, we also detected nestin mRNA and protein in the ESCC cell lines, Eca-109 and TE-1. 


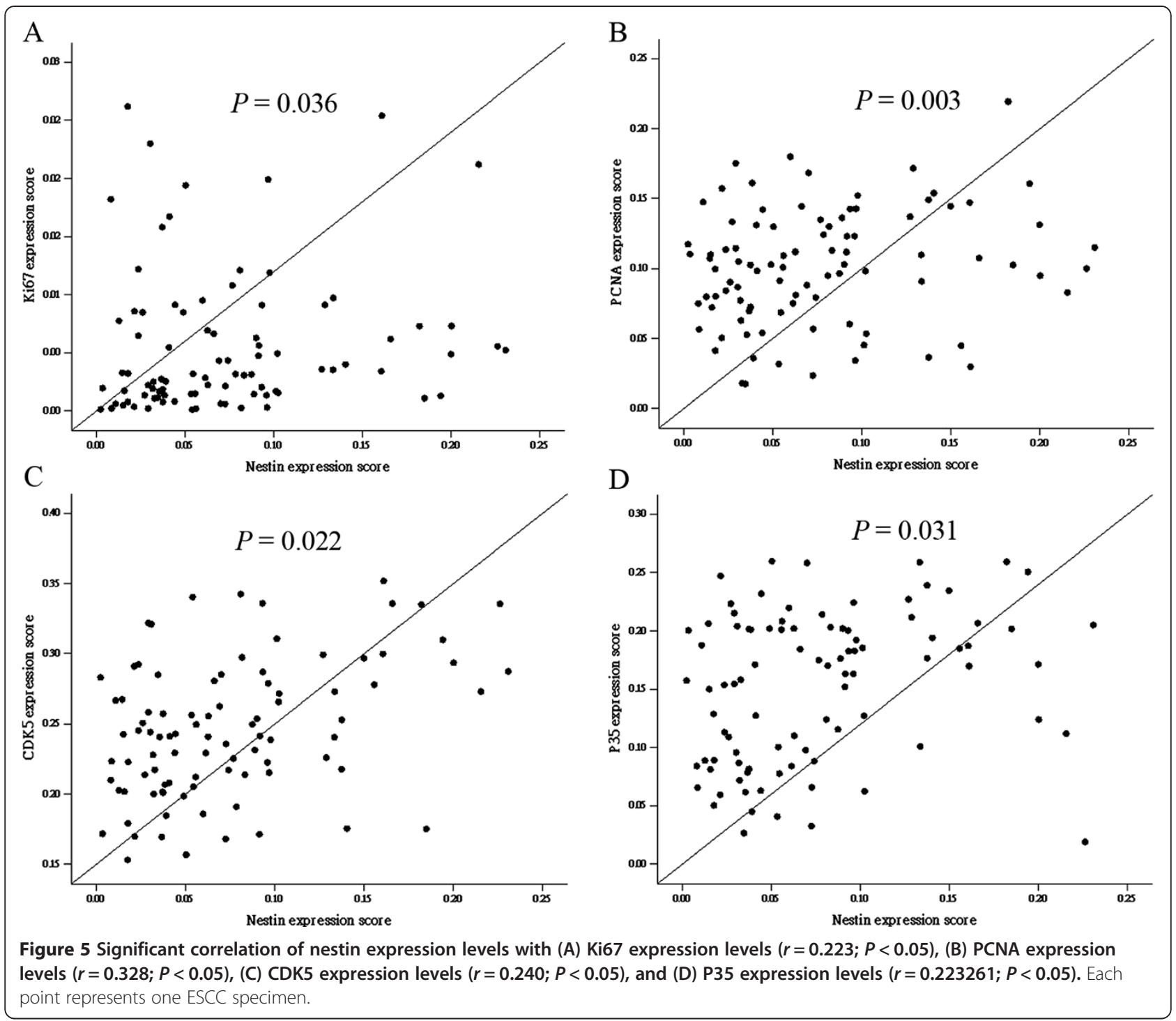

Secondly, we showed that the nestin phenotype is significantly associated with poor prognosis in Chinese patients with ESCC. Some studies have reported that nestin expression in vascular sarcoma, pancreatic cancer, and gastrointestinal stromal tumors is closely correlated with the degree of malignancy and patient prognosis $[14,15,30]$. In our study, we found significant differences in both MST and PFS between patients in nestin-positive and nestin-negative groups. Furthermore, a multivariate statistical analysis showed that nestin was a significant prognostic indicator independent of other clinical and pathological factors. Therefore, our experiments showed that Chinese ESCC patients with nestin-positive tumors had a worse prognosis than those in the nestin-negative group.

Thirdly, we found that the nestin phenotype of ESCC cells was closely related to malignant proliferation.
Recent studies have reported that tumor cells with high expression of nestin show rapid proliferation [31]. In our experiments, we used Ki67 and PCNA as proliferative markers. Ki67, a nuclear protein that has been widely used in tumor biology as a marker of tumor-cell proliferation, plays an important role in regulating cell differentiation [32]. PCNA, a trimer that forms a clamp around DNA and promotes DNA polymerase-dependent DNA replication, is highly expressed in proliferating cells, especially tumor cells; in the latter, high expression of PCNA is correlated with high malignancy [33-35]. Among ESCC clinical specimens, $56.9 \%$ and $60.2 \%$ were positive for Ki67 and PCNA, respectively. Moreover, a quantitative analysis revealed that Ki67 and PCNA expression were positively correlated with nestin expression. Taken together, these findings indicate that the nestin phenotype is positively correlated with ESCC cell proliferation, 


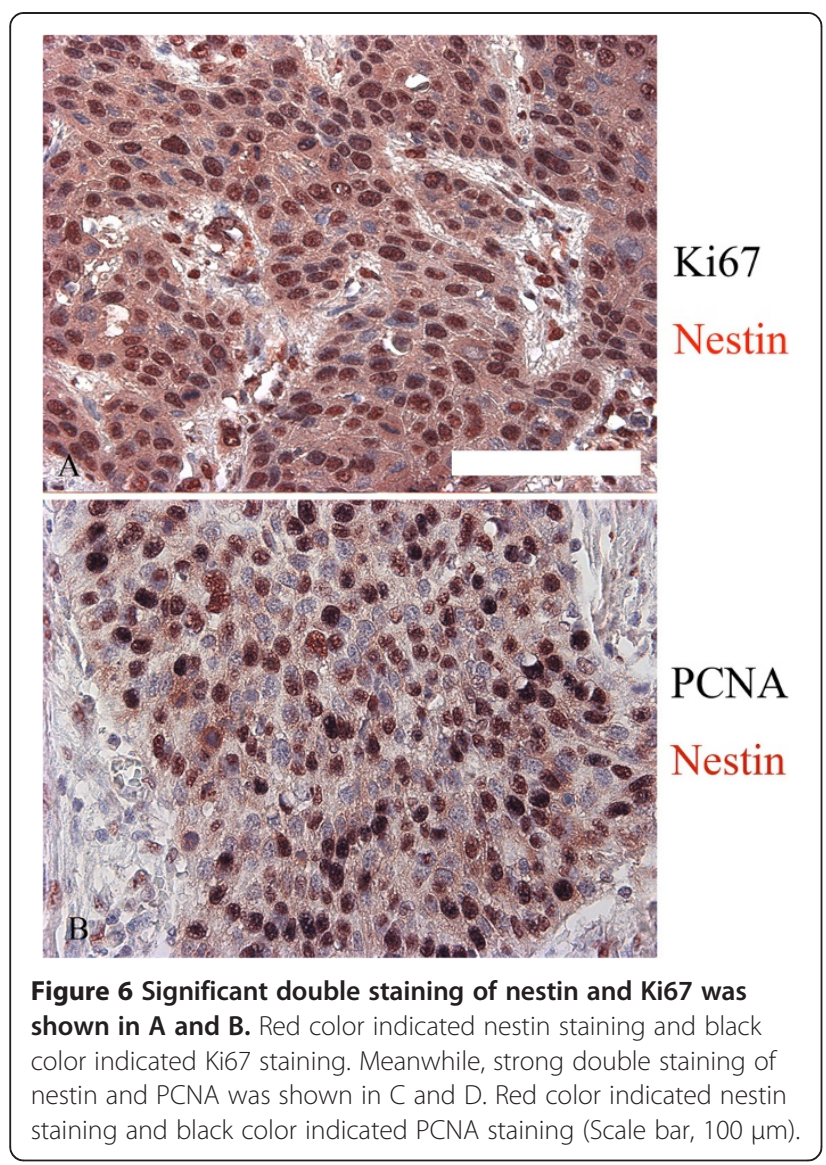

providing preliminary evidence for a role for nestin in regulating ESCC cell proliferation.

We also investigated possible association of nestin with tumor cells apoptosis by examining the expression of CDK5 and P35 using immunohistochemistry. CDK5 is a member of the cyclin-dependent kinase family that is preferentially expressed in terminally differentiated cells, such as neurons, muscle, and lens fibers [36-40]. CDK5 activity is mainly regulated by its association with P35 (which is often, but not exclusively, associated with neural tissues) and to lesser degree by P39 [40]. CDK5 is able to perform substrate phosphorylation in different cellular compartments, including the cytoplasm and nucleus $[41,42]$. Some reports suggest that CDK5 may have a significant role in the regulation of breast, lung, and prostate cancer cell proliferation, apoptosis, migration, and invasion [43-45]. We found that $53.8 \%$ and $48.4 \%$ of ESCC cases were positive for the expression of CDK5 and P35 expression, respectively; CDK5 and P35 were detected in both nuclei and cytoplasm, consistent with a previous report [46]. Importantly, CDK5 and P35 expression were positively correlated with nestin expression, suggesting the possibility that nestin promotes ESCC cell apoptosis. In this latter context, it is conceivable that nestin might serve as a nuclear scaffold for CDK5 that could affect the organization, stability, and activity of the CDK5 and P35 signaling complex, as suggested by the reported importance of nuclear localization in the activity of Cdk5 [42,47].

Based on the data that the nestin phenotype is closely correlated with ESCC cell proliferation and apoptosis, by extension, our results suggest an association with metastasis, consistent with recent reports that tumor cells with high expression of nestin more readily metastasize. Metastasis is a gradual and complex process that requires a collection of dispersed tumor cells with several capabilities, including invasion into the circulatory system from the primary tumor, survival in the circulation, exudation at a distant site, and proliferation in an alien and inhospitable environment $[47,48]$. The ability of tumor cells to migrate and invade into the circulatory system from the primary tumor is related to tumor cell motility. Cell motility is important during embryonic development as well as in physiological processes of many adult organs. This kind of motility is regulated by numerous mechanisms, including a link between the epithelial cell membrane and the cytoskeleton. One such mechanism is that mediated by intermediate filaments. For example, cytoskeletal reorganization of actin filaments is very important for cell motility and also underlies most cell migration $[47,48]$. As a member of the class VI family of intermediate filament proteins and a cytoskeletal element, nestin has an effect in tumor cells similar to that of actin. When tumor cells successfully invade the circulatory system from the original tumor and reach an alien immune-surveillance environment, their ability to survive-largely a reflection of their ability to proliferate-becomes the key to their successful metastasis in this environment. In our experiments, nestin expression in ESCC samples was positively correlated with Ki67 and PCNA expression, predicting that nestin-positive esophageal squamous cells would proliferate more rapidly than nestinnegative cells. We also found that MST and PFS of nestin-positive ESCC patients were shorter than those of nestin-negative patients. The current view is that the primary reasons for the failure of ESCC surgical treatments are recurrence and metastasis [4]. Our preliminary studies demonstrating that nestin expression is positively correlated with the proliferative and apoptotic behavior of ESCC provide a possible explanation for the prognostic value of nestin. Collectively, our findings demonstrate that nestin-expressing tumor cells are important for proliferation, apoptosis, migration, and metastasis in ESCC.

While our results suggest that nestin contributes to the proliferation and apoptosis in ESCC cells, other aspects of metastasis, such as angiogenesis, lymphangiogenesis and tumor metabolism, were not directly 
examined. However, in view of our findings, the role of nestin needs to be considered in clinical diagnosis and as a potential new target for cancer therapy.

In summary, we observed nestin-positive tumor cells in a portion of ESCC samples in Chinese population and demonstrated a significant association of nestin expression with the subset of Chinese ESCC patients displaying poor outcomes and high levels of proliferative markers. Our preliminary findings of positive correlations between nestin expression and CDK5 and P35 expression further support the tentative conclusion that nestin likely promotes ESCC cell apoptosis. Collectively, our data suggest that tumor cells expressing nestin promote ESCC cell proliferation and apoptosis, which may constitute a key mechanism of nestin-mediated metastasis in esophageal cancer cells. Targeted regulation of nestin may thus have therapeutic applications in the treatment of human esophageal cancer.

\section{Abbreviations}

CDK5: Cyclin dependent kinase-5; EAC: Esophageal adenocarcinoma; EC: Esophageal cancer; ESCC: Esophageal squamous cell carcinoma; MST: Median survival time; PCNA: Proliferating cell nuclear antigen; PFS: Progression-free survival; TNM: Tumor-node-metastasis.

\section{Competing interests}

All authors have full access to all of the data in the study and have final responsibility for the decision to submit for publication. The authors have no conflict of interest.

\section{Author contributions}

BZ, TW, and ZC conceived the study, participated in analysis of NSCLC specimens and cell lines, and drafted the manuscript. BZ, TW, JZ, and WY performed histopathological analysis of tumor samples and RT-PCR assay. BZ, $\mathrm{XL}$, and $\mathrm{SZ}$ participated in the patient inclusion and manuscript preparation. TW, WY, and WL conducted Western blot analysis and the cell proliferation assay. BZ and ZC performed statistical analysis of all data. APX and ZC designed the experiments, coordinated the study, and drafted the manuscript. All authors have read and approved the final version of the manuscript.

\section{Acknowledgements}

This study was supported by grants from the National Basic Research Program of China (No. 2009CB522100 and 2010CB945400), the National Natural Science Foundation of China (No. 81101774, 30971675, 30900729, and 31171398), and the Key Scientific and Technological Projects of Guangdong Province (No. 2007A032100003).

\section{Author details}

${ }^{1}$ Department of Thoracic Surgery, the Fifth Affiliated Hospital, Sun Yat-sen University, Zhuhai, Guangdong 519000, China. ${ }^{2}$ Center for Stem Cell Biology and Tissue Engineering, Sun Yat-sen University, Key Laboratory for Stem Cells and Tissue Engineering, Ministry of Education, Guangzhou, Guangdong, China. ${ }^{3}$ Department of Biochemistry, Zhongshan Medical School, Sun Yat-sen University, Guangzhou, Guangdong, China. ${ }^{4}$ Department of Thoracic Surgery, the First Affiliated Hospital, Sun Yat-sen University, Guangzhou, Guangdong 510080, China. ${ }^{5}$ Lung Cancer Research Center of Sun Yat-sen University, Guangzhou, Guangdong 510080, China. ${ }^{6}$ Department of Cardiothoracic Surgery of East Division, the First Affiliated Hospital, Sun Yat-sen University, Guangzhou, Guangdong 510080, China. ${ }^{7}$ Guangzhou Research Institute of Traumatic Surgery, the Fourth Affiliated Hospital, Ji'nan University, Guangzhou, Guangdong 510220, China. ${ }^{8}$ Department of Anesthesiology and Operating Room of East Division, the First Affiliated Hospital, Sun Yat-sen University, Guangzhou, Guangdong, China.

Received: 26 April 2014 Accepted: 16 June 2014

Published: 20 June 2014

\section{References}

1. Daly JM, Fry WA, Little AG, Winchester DP, McKee RF, Stewart AK, Fremgen AM: Esophageal cancer: results of an American College of Surgeons Patient Care Evaluation Study. J Am Coll Surg 2000, 190(5):562-572

2. Li LW, Li YY, Li XY, Zhang CP, Zhou Y, Lu SH: A novel tumor suppressor gene ECRG4 interacts directly with TMPRSS11A (ECRG1) to inhibit cancer cell growth in esophageal carcinoma. BMC Cancer 2011, 11:52-56.

3. Wilson M, Rosato EL, Chojnacki KA, Chervoneva I, Kairys JC, Cohn HE, Rosato FE, Berger AC: Prognostic significance of lymph node metastases and ratio in esophageal cancer. J Surg Res 2008, 146(1):11-15.

4. Nakagawa S, Kanda T, Kosugi S, Ohashi M, Suzuki T, Hatakeyama K: Recurrence pattern of squamous cell carcinoma of the thoracic esophagus after extended radical esophagectomy with three field lymphadenectomy. Am Coll Surg 2004, 198(2):205-211.

5. Lodish H, Berk A, Kaiser CA, Krieger M, Scott MP, Bretscher A, Ploegh H, Matsudaira P: Molecular Cell Biology, Cancer Sections 25. 6th edition. New York, NY: W. H. Freeman \& Company; 2008:1-25. 5.

6. Guérette $D$, Khan PA, Savard PE, Vincent M: Molecular evolution of type VI intermediate filament proteins. BMC Evol Biol 2007, 7:164-169.

7. Cattaneo E, McKay R: Proliferation and differentiation of neuronal stem cells regulated by nerve growth factor. Nature 1990, 347(6295):762-765.

8. Park D, Xiang AP, Mao FF, Zhang L, Di CG, Liu XM, Shao Y, Ma BF, Lee JH, Ha KS, Walton N, Lahn BT: Nestin is required for the proper self-renewal of neural stem cells. Stem Cells 2010, 28(12):2162-2171.

9. Shimizu T, Sugawara K, Tosaka M, Imai H, Hoya K, Takeuchi T, Sasaki T, Saito N: Nestin expression in vascular malformations: a novel marker for proliferate endothelium. Neurol Med Chir (Tokyo) 2006, 46(3):111-117.

10. Mokry J, Cizkova D, Filip S, Ehrmann J, Osterreicher J, Kolár Z, English D: Nestin expression by newly formed human blood vessels. Stem Cells Dev 2004, 13(6):658-664.

11. Amoh Y, Yang M, Li L, Reynoso J, Bouvet M, Moossa AR, Katsuoka K, Hoffman RM: Nestin-linked green fluorescent protein transgenic nude mouse for imaging human tumor angiogenesis. Cancer Res 2005, 65(12):5352-5357.

12. Takakuwa O, Maeno K, Kunii E, Ozasa H, Hijikata H, Uemura T, Kasai D, Ohkubo H, Miyazaki M, Oguri T, Niimi A: Involvement of intermediate filament nestin in cell growth of small-cell lung cancer. Lung cancer 2013, 81(2):174-179.

13. Krüger K, Stefansson IM, Collett K, Arnes JB, Aas T, Akslen LA: Microvessel proliferation by co-expression of endothelial nestin and $\mathrm{Ki}-67$ is associated with a basal-like phenotype and aggressive features in breast cancer. Breast 2013, 22(3):282-288.

14. Mangiola A, Lama G, Giannitelli C, De Bonis P, Anile C, Lauriola L, La Torre G, Sabatino G, Maira G, Jhanwar-Uniyal M, Sica G: Stem cell marker nestin and c-Jun NH2-terminal kinases in tumor and peritumor areas of glioblastoma multiforme: possible prognostic implications. Clin Cancer Res 2007, 13(23):6970-6977.

15. Ohike N, Sato M, Hisayuki T, Imataka H, Sato S, Wada Y, Saito K, Takahashi M, Tajiri T, Kunimura T, Morohoshi T: Immunohistochemical analysis of Nestin and c-kit and their significance in pancreatic tumors. Pathol Int 2007, 57(9):589-593.

16. Rani SB, Mahadevan A, Anilkumar SR, Raju TR, Shankar SK: Expression of nestin-a stem cell associated intermediate filament in human CNS tumors. Indian J Med Res 2006, 124(3):269-280.

17. Klein WM, Wu BP, Zhao S, Wu H, Klein-Szanto AJ, Tahan SR: Increased expression of stem cell markers in malignant melanoma. Mod Pathol 2007, 20(1):102-107.

18. Chen Z, Wang T, Luo H, Lai Y, Yang X, Li F, Lei Y, Su C, Zhang X, Lahn BT, Xiang AP: Expression of nestin in lymph node metastasis and lymphangiogenesis in non-small cell lung cancer patients. Hum Pathol 2010, 41(5):737-744.

19. Chen Z, Wang J, Cai L, Zhong B, Luo H, Hao Y, Yu W, Wang B, Su C, Lei Y, Amos $E B$, Xiang AP, Wang T: Role of the stem cell-associated intermediate filament nestin in malignant proliferation of non-small cell lung cancer. PLOS One 2014, 9(2):e85584. doi:10.1371/journal.pone.0085584. eCollection 2014.

20. Edge S, Byrd DR, Compton CC, Fritz AG, Greene FL, Trotti A: Esophagus and esophagogastric junction. In AJCC Cancer Staging Manual. 7th edition. New York, NY: Springer; 2010:103-111.

21. Sobin LH, Wittekind C: TNM classification of malignant tumors. 6th edition. New Jersey: John Wiley \& Sons; 2002. 
22. Yang XH, Wu QL, Yu XB, Xu CX, Ma BF, Zhang XM, Li SN, Lahn BT, Xiang AP: Nestin expression in different tumours and its relevance to malignant grade. J Clin Pathol 2008, 61:467-473.

23. Elias JM, Margiotta M, Gaborc D: Sensitivity and detection efficiency of the peroxidase antiperoxidase (PAP), avidin-biotin peroxidase complex (ABC), and peroxidase-labeled avidin-biotin (LAB) methods. Am J Clin Pathol 1989, 92(1):62-67.

24. Carter JH, Douglass LE, Deddens JA, Colligan BM, Bhatt TR, Pemberton JO, Konicek S, Hom J, Marshall M, Graff JR: Pak-1 expression increases with progression of colorectal carcinomas to metastasis. Clin Cancer Res 2004, 10(10):3448-3456.

25. Wang $\mathrm{Q}$, Zeng $Y J$, Huo $\mathrm{P}, \mathrm{Hu} J \mathrm{~L}$, Zhang $\mathrm{JH}$ : A specialized plug-in software module for computer-aided quantitative measurement of medical images. Med Eng Phy 2003, 25(10):887-892.

26. Wiese C, Rolletschek A, Kania G, Blyszczuk P, Tarasov KV, Tarasova Y, Wersto RP, Boheler KR, Wobus AM: Nestin expression: a property of multi-lineage progenitor cells? Cell Mol Life Sci 2004, 61(19-20):2510-2522.

27. Suzuki S, Namiki J, Shibata S, Mastuzaki Y, Okano H: The neural stem/ progenitor cell marker nestin is expressed in proliferative endothelial cells, but not in mature vasculature. J Histochem Cytochem 2010, 58(8):721-730

28. Li H, Cherukuri P, Li N, Cowling V, Spinella M, Cole M, Godwin AK, Wells W, DiRenzo J: Nestin is expressed in the basal/myoepithelial layer of the mammary gland and is a selective marker of basal epithelial breast tumors. Cancer Res 2007, 67(2):501-510.

29. Ryuge S, Sato Y, Wang GQ, Matsumoto T, Jiang SX, Katono K, Inoue H, Satoh $Y$, Masuda N: Prognostic significance of nestin expression in resected non-small cell lung cancer. Chest 2011, 139(4):862-869.

30. Strojnik T, Rosland GV, Sakariassen PO, Kavalar R, Lah T: Neural stem cells markers, nestin and musashi protein, in the progression of human glioma: correlation of nestin with prognosis of patient survival. Surg Neurol 2007, 68:133-143.

31. Wei LC, Shi M, Cao R, Chen KW, Chan YS: Nestin small interfering RNA (siRNA) reduces cell growth in cultured astrocytoma cells. Brain Res 2008, 1196:103-112.

32. Gerdes J: Ki-67 and other proliferation markers useful for immunohistological diagnostic and prognostic evaluations in human malignancies. Semin Cancer Biol 1990, 1(3):199-206.

33. Krishna TSR, Kong XP, Gary S, Burgers PM, Kuriyan J: Crystal structure of the eukaryotic DNA polymerase processivity factor PCNA. Cell 1994, 79(7):1233-1243.

34. Stoimenov I, Helleday T: PCNA on the crossroad of cancer. Biochem Soc Trans 2009, 37(Pt 3):605-613.

35. Stuart-Harris R, Caldas C, Pinder SE, Pharoah P: Proliferation markers and survival in early breast cancer: a systematic review and metaanalysis of 85 studies in 32,825 patients. Breast 2008, 17(4):323-334

36. Meyerson M, Enders GH, Wu CL, Su LK, Gorka C, Nelson C, Harlow E, Tsai LH: A family of human cdc2-related protein kinases. EMBO J 1992, 11(80):2909-2917.

37. Tsai LH, Takahashi T, Caviness VSJ, Harlow E: Activity and expression pattern of cyclin-dependent kinase 5 in the embryonic mouse nervous system. Development 1993, 119(4):1029-1040.

38. Lazaro JB, Kitzmann M, Poul MA, Vandromme M, Lamb NJC, Fernandez A: Cyclin dependent kinase $5, \mathrm{cdk} 5$, is a positive regulator of myogenesis in mouse C2 cells. J Cell Sci 1997, 110(Pt 10):1251-1260.

39. Gao CY, Zakeri Z, Zhu Y, He HY, Zelenka PS: Expression of Cdk-5, p35, and Cdk5-associated kinase activity in the developing rat lens. Dev Genet 1997, 20(3):267-275.

40. Tsai LH, Delalle I, Caviness VS, Chae T, Harlow E: p35 is a neural-specific regulatory subunit of cyclin-dependent kinase 5. Nature 1994, 371(6496):419-423.

41. Fu X, Choi YK, Qu D, Yu Y, Cheung NS, Qi RZ: Identification of nuclear import mechanisms for the neuronal Cdk5 activator. J Biol Chem 2006 281(51):39014-39021.

42. Zhang J, Cicero SA, Wang L, Romito-Digiacomo RR, Yang Y, Herrup K: Nuclear localization of Cdk5 is a key determinant in the postmitotic state of neurons. Proc Natl Acad Sci U S A 2008, 105(25):8772-8777.

43. Goodyear S, Sharma MC: Roscovitine regulates invasive breast cancer cell (MDA-MB231) proliferation and survival through cell cycle regulatory protein cdk5. Exp Mol Pathol 2007, 82:25-32.
44. Demelash A, Rudrabhatla P, Pant HC, Wang X, Amin ND, McWhite CD, Naizhen X, Linnoila Rl: Achaete-scute homologue-1 (ASH1) stimulates migration of lung cancer cells through Cdk5/p35 pathway. Mol Biol Cell 2012, 6:2856-2866

45. Strock CJ, Park JI, Nakakura EK, Bova GS, Isaacs JT, Ball DW, Nelkin BD: Cyclin-dependent kinase 5 activity controls cell motility and metastatic potential of prostate cancer cells. Cancer Res 2006, 66:7509-7515.

46. Sahlgren CM, Pallari HM, He T, Chou YH, Goldman RD, Eriksson JE: A nestin scaffold links Cdk5/p35 signaling to oxidant-induced cell death. EMBO J 2006, 25(20):4808-4819.

47. Bhave SL, Teknos TN, Pan Q: Molecular parameters of head and neck cancer metastasis. Crit Rev Eukaryot Gene Expr 2011, 21(2):143-153.

48. Yamazaki D, Kurisu S, Takenawa T: Regulation of cancer cell motility through actin reorganization. Cancer Sci 2005, 96:379-86.

doi:10.1186/1475-2867-14-57

Cite this article as: Zhong et al.: Contribution of nestin positive esophageal squamous cancer cells on malignant proliferation, apoptosis, and poor prognosis. Cancer Cell International 2014 14:57.

\section{Submit your next manuscript to BioMed Central and take full advantage of:}

- Convenient online submission

- Thorough peer review

- No space constraints or color figure charges

- Immediate publication on acceptance

- Inclusion in PubMed, CAS, Scopus and Google Scholar

- Research which is freely available for redistribution 